\title{
Communicable Diseases Report, New South Wales, for March and April 2007
}

\section{Communicable Diseases Branch, NSW Department of Health}

For updated information, including data and facts on specific diseases, visit www.health.nsw.gov.au and click on Infectious Diseases.

\section{Trends}

Figure 1 and Tables 1 and 2 show reports of communicable diseases received through to the end of April 2007 in NSW.

\section{Hepatitis A clinic}

In March, Sydney South West Public Health Unit (PHU) initiated a large immunoglobulin clinic following identification of a sushi chef who had been working whilst infectious with hepatitis A. Following a media release, over 400 people received immunoglobulin which can prevent the development of hepatitis A if given within 14 days of exposure.

\section{Salmonellosis outbreak}

In late March, Sydney South West PHUwas notified of 10 people with gastroenteritis who presented to Concord Hospital. All cases reported eating pork or chicken rolls from a Sydney bakery. NSW Food Authority officers inspected the bakery and issued a prohibition order restricting the sale of pork and chicken rolls. Over 300 people were reported to the PHU with symptoms of salmonellosis (including diarrhoea, abdominal pain and vomiting). Laboratory results identified Salmonella Typhimurium phage type 9 in human, food and environmental samples. The source of contamination remains unclear.

\section{HCV investigation}

In late February 2007, a doctor notified the South Eastern Sydney and Illawarra PHU that three of his patients had been diagnosed with acute hepatitis $\mathrm{C}$ infection. All received parenteral vitamin therapy at his clinic. The patients, all woman in their 40s and 50s, were diagnosed in January 2007, February 2007 and late 2004.

PHU staff interviewed the cases in detail about risks, but no obvious source of infection was identified. All cases had received intramuscular vitamin $\mathrm{B}$, intramuscular magnesium and intravenous vitamin $\mathrm{C}$ injections at the clinic.

An investigation was initiated to determine if hepatitis transmission had occurred in the practice, and if so, how, and whether other patients may be at risk. The doctor cooperated with the investigation and agreed to cease all vitamin therapy and venipunctures as a precautionary measure.

Laboratory tests comparing viral strains between patients were initiated. A review of infection control practices and interviews with staff could not identify a specific incident with the potential for transmission. As a precaution, staff training and procedural changes were recommended at the clinic. Investigators began contacting patients who received vitamin injections at the clinic on days when transmission was suspected of having occurred.

Hepatitis $\mathrm{C}$ is a viral infection of the liver that is primarily transmitted parenterally. Sexual transmission is rare and more likely when there is contact with blood. ${ }^{1}$ In $60-70 \%$ of cases, hepatitis $\mathrm{C}$ infection is asymptomatic. A total of $20-30 \%$ of cases may have jaundice and 10-20\% may experience non-specific symptoms such as anorexia, malaise or abdominal pain. Clinical illness occurs on average from six to seven weeks following exposure to the virus. The majority of patients infected with hepatitis $\mathrm{C}$ without treatment go on to develop a chronic infection, ${ }^{2}$ and studies indicate that cirrhosis may develop in 4-24\% of people after 20 years of infection. ${ }^{3}$ Recent advances, in combination antiviral treatment, mean that a cure can be effected in up to two thirds of cases, depending on the viral genotype and stage of the infection. ${ }^{4}$ There is currently no vaccine for hepatitis $C$. The investigation continues.

\section{References}

1. Dore GJ, Law M, MacDonald M, Kaldor JM. Epidemiology of hepatitis C virus infection in Australia. J Clin Virol 2003; 26(2): 171-84. doi:10.1016/S1386-6532(02)00116-6

2. Recommendations for Prevention and Control of Hepatitis C Virus (HCV) Infection and HCV-Related Chronic Disease. Available at http://www.cdc.gov/mmwr/preview/mmwrhtml/ 00055154.htm [Verified 4 June 2007].

3. Bialek SR, Terrault NA. The changing epidemiology and natural history of hepatitis C virus infection. Clin Liver Dis 2006; 10(4): 697-715. doi:10.1016/j.cld.2006.08.003

4. Pol S, Bourliere M. Optimizing treatment outcomes in chronic hepatitis C: management of non-response. Antivir Ther 2006; 11(8): 955-70. 
Figure 1. Reports of selected communicable diseases, NSW, January 2002 to April 2007, by month of onset Preliminary data: case counts in recent months may increase because of reporting delays. Laboratory-confirmed cases only, except for measles, meningococcal disease and pertussis.

$\mathrm{BFV}=$ Barmah Forest virus infections, RRV $=$ Ross River virus infections. Lab Conf $=$ laboratory confirmed

Men Gp C and Gp B = meningococcal disease due to serogroup $C$ and serogroup $B$ infection, other/unk = other or unknown serogroups. NB: multiple series in graphs are stacked, except gastroenteritis outbreaks.

NB: Outbreaks are more likely to be reported by nursing homes and hospitals than by other institutions.
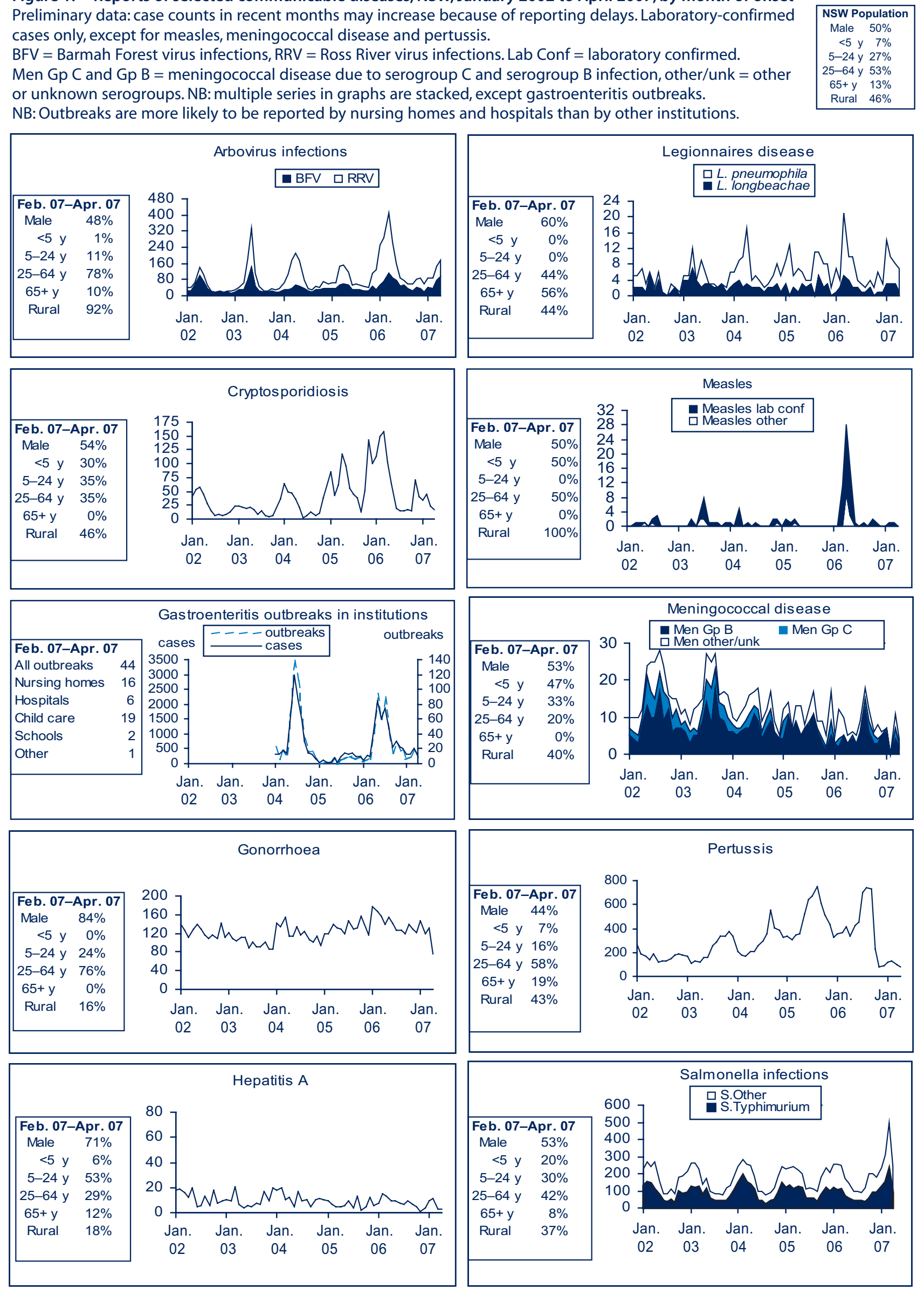
Table 1. Reports of notifiable conditions received in March 2007 by Area Health Services

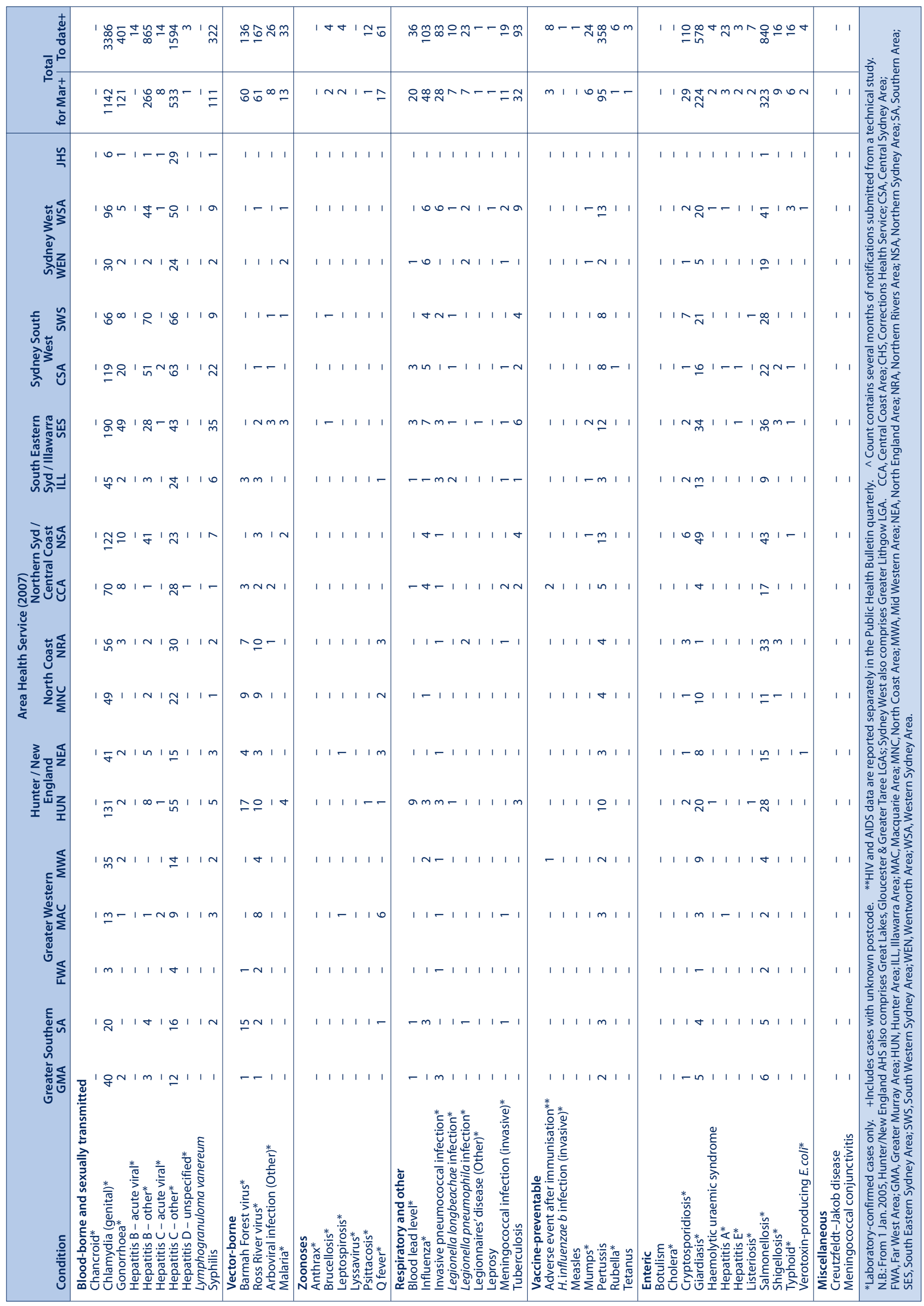


Table 2. Reports of notifiable conditions received in April 2007 by Area Health Services

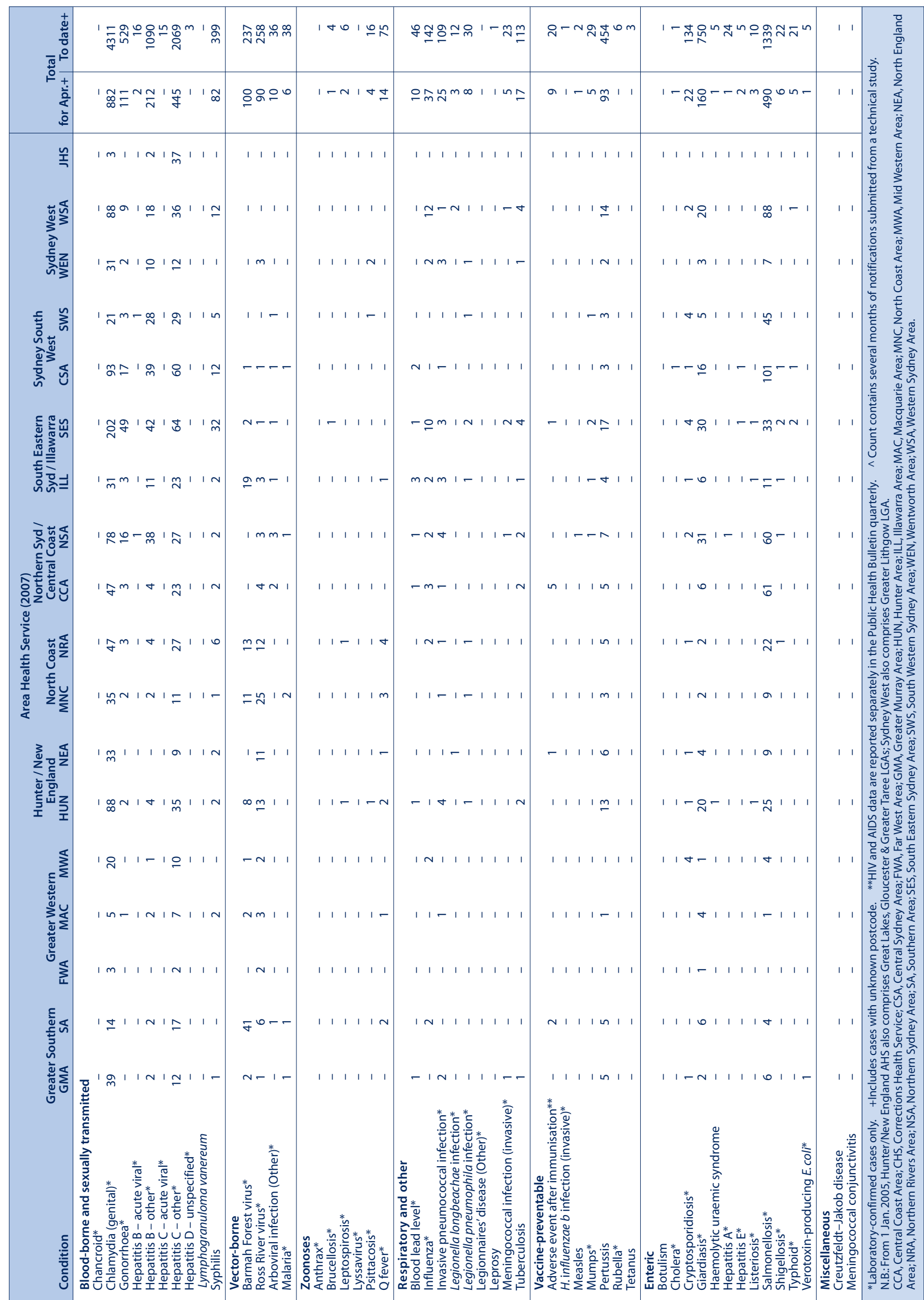

